\title{
HUBUNGAN PERILAKU PENCEGAHAN DENGAN KEJADIAN KOMPLIKASI AKUT PADA PASIEN DIABETES MELITUS
}

\author{
I Wayan Suardana*, I Wayan Mustika, Dewa Ayu Sri Utami \\ Politeknik Kesehatan Kemenkes Denpasar Jurusan Keperawatan, \\ Denpasar, Indonesia \\ *) Email: suardanawayan@yahoo.com
}

\begin{abstract}
ABSTRAK
Tujuan: menganalisis hubungan perilaku pencegahan dengan kejadian komplikasi akut pada pasien Diabetes Melitus (DM). Metode: Jenis penelitian yang digunakan adalah penelitian correlational. Tehnik sampling yang digunakan adalah purposive sampling dengan jumlah sampel 85 orang. Instrumen yang digunakan dikembangkan dari instrumen The Diabetes Self-Management Questionnaire (DSMQ) untuk menilai perilaku pencegahan pada pasien DM dan instrumen untuk menilai pengetahuan, sikap, dan perilaku. Data dianalisis secara univariate dan bivariat (chi-square test). Hasil: Hasil penelitian ini menunjukkan bahwa ada hubungan perilaku pencegahan dengan kejadian komplikasi akut pada pasien DM. Pasien DM yang memiliki perilaku pencegahan yang cukup (60-79\%) mempunyai 4,73 kali untuk mengalami komplikasi akut pada DM. Diskusi: Tindakan pengendalian DM untuk mencegah komplikasi sangat diperlukan, khususnya dengan menjaga tingkat gula darah sedekat mungkin dengan normal. Kesimpulan: Perilaku pencegahan yang baik dapat mencegah terjadinya komplikasi pada penderita DM Type II.
\end{abstract}

Kata Kunci: Perilaku, pencegahan, komplikasi, Diabetes Melitus

\section{Relationship Between Preventive Behaviour with Acute Complications Occurrence in Diabetes Mellitus Patients}

\section{ABSTRACT}

Aim: to analyze the relationship between preventive behavior with the incidence of acute complications in DM patients. Method: The type of research used is correlational research. The sampling technique used was purposive sampling with 85 samples. The Instruments of this research are developed from The Diabetes Self-Management Questionnaire (DSMQ) to assess the preventive behaviour in DM patients and instrument to assess knowledge, attitude, and behaviour. Data analysis using univariate and bivariate (chi-square test) analysis. Results: The results of this study indicate that there is a correlation between preventive behavior and the incidence of acute complications in DM patients. DM patients who was categorized in moderate preventive behaviour (60-79\%) have 4.73 times experience acute complication in DM. Discusion: preventive behavior to prevent complication is necessary, especially by maintaining the blood glucose as close as possible to normal level. Conclusion: Good preventative behavior could prevent complications in patients with Type II of DM.

Keywords: behaviour, prevention, complication, diabetes mellitus

\section{LATAR BELAKANG}

Diabetes Mellitus (DM) termasuk penyakit tidak menular yang lebih dikenal sebagai pembunuh manusia secara diamdiam atau "silent killer" dan "mother of disease" karena merupakan induk atau ibu dari penyakit-penyakit lainnya seperti hipertensi, penyakit jantung, dan pembuluh darah, stroke, gagal ginjal dan kebutaan. World Health Organization (WHO) pada tahun 2016 menjelaskan bahwa jumlah penderita DM di dunia mencapai 347 juta 
jiwa dan lebih dari 80\% kematian akibat DM terjadi pada negara miskin dan berkembang. Data dari International Diabetes Federation (IDF) menunjukkan bahwa Indonesia menempati urutan ketujuh penderita DM terbanyak di dunia dengan jumlah penderita 7,6 juta orang pada rentang usia sekitar 2079 tahun dan yang mengalami komplikasi akut sebanyak 50\% (International Diabetes Federation, 2013).

Dinas Kesehatan Provinsi Bali menyatakan jumlah penderita DM di Bali mengalami peningkatan dari tahun 2013 sampai 2015 yaitu tercatat sebanyak 2.852 orang dan 4.545 orang. Kasus baru DM yang tercatat dari tahun 2015 sampai 2016 yaitu 481 orang dan 779 orang (Dinas Kesehatan Kabupaten Klungkung, 2016). Data yang tercatat pada Puskesmas Dawan I menunjukkan kasus baru penderita DM di Wilayah Kerja Puskesmas Dawan I pada tahun 2015 sampai 2016 mengalami peningkatan yaitu sebanyak 158 orang dan 556 orang (Puskesmas Dawan I, 2016).

Kadar glukosa darah yang tidak dikelola dengan baik dapat menimbulkan berbagai komplikasi, yaitu komplikasi akut dan komplikasi kronis. Komplikasi akut dibagi menjadi dua yaitu hiperglikemia dan hipoglikemia. Komplikasi akut ini bersifat mendadak dan jangka waktu yang pendek apabila tidak ditangani segera maka akan menyebabkan kecacatan sampai kematian. Adapun data mengenai komplikasi akut berdasarkan Riskesdas tahun 2013 diantaranya pada komunitas di Amerika Serikat, Rochester, menunjukkan bahwa Insiden Ketoasidosis Diabetik (KAD) sebesar 8/1.000 pasien DM pertahun untuk semua kelompok umur, sedangkan untuk kelompok umur kurang dari 30 tahun sebesar 13,4/1.000 pasien DM per tahun (Kementerian Kesehatan RI, 2013).

Jumlah pasien DM yang mengalami hipoglikemia di Indonesia senada dengan prevalensi diabetes di Indonesia yaitu $1,1 \%$ secara nasional dan $5,7 \%$ penduduk perkotaan di Indonesia. Hipoglikemia lebih sering terjadi pada DM tipe 1 dengan angka kejadian 10\%-30\% pasien per tahun dengan angka kematian 3\%-4\% (Goldman \& Schafer, 2012), sedangkan pada DM tipe 2 angka kejadiannya 1,2\% pasien per tahun (Berber, dkk, 2001). Tindakan pengendalian DM untuk mencegah komplikasi sangat diperlukan, khususnya dengan menjaga tingkat gula darah sedekat mungkin dengan normal. Pengendalian gula darah ini sangat sulit untuk dipertahankan. Kejadian ini disebabkan tidak disiplinnya penderita dalam penatalaksanaan DM (Waspadji, 2009). Grabber, dkk (1977) dikutip dari Rizal \& Buana (2008), mengatakan bahwa pendidikan pasien umumnya dianggap sebagai komponen penting dari manajemen diabetes. Namun, analisis tentang peran pendidikan/pengetahuan dalam mengendalikan diabetes masih terbatas. Pasien yang memiliki pengetahuan yang baik mengenai DM, tapi perubahan dalam mengendalikan diabetes dan parameter klinis lain belum tentu diikuti.

Melihat tingginya kejadian penderita DM di Puskesmas Dawan I pada tahun 2015 sampai dengan tahun 2016 dan hasil dari studi pendahuluan yaitu tujuh dari sepuluh responden pernah mengalami komplikasi akut, yaitu lima orang pernah mengalami kadar gula lebih dari 200 mg/dl dan dua orang pernah mengalami kadar gula rendah dari $100 \mathrm{mg} / \mathrm{dl}$ dilihat dari hasil pemeriksaan kadar gula darah. Puskesmas Dawan I sudah melakukan beberapa upaya untuk mencegah terjadinya komplikasi DM baik dari komplikasi akut maupun kronis yaitu dengan menjalankan program pengendalian DM untuk pasien datang (kasus baru) dan pasien kasus lama. Salah satu upaya yang dianjurkan adalah pelaksanaan kontrol DM.

Banyak faktor yang berhubungan 
dengan penderita DM tentunya membuat tindakan pengelolaan penyakit hendaklah dilakukan dengan cermat untuk dapat mencegah terjadinya komplikasi terutama pada komplikasi akut. Mengingat komplikasi akut merupakan komplikasi yang gejalanya bersifat mendadak, jika tidak ditangani dengan segera dan tepat maka akan menyebabkan kecacatan bahkan dapat menyebabkan kematian. Selain itu, dari beberapa hasil penelitian yang dilakukan mengenai komplikasi dari DM dan variabel yang terkait menunjukkan hasil yang berbeda-beda, sehingga peneliti tertarik meneliti mengenai Hubungan perilaku pencegahan dengan kejadian komplikasi akut pada penderita DM di Puskesmas Dawan I.

\section{METODE}

Jenis penelitian ini correlational study dengan pendekatan terhadap subjek penelitian adalah cross sectional. Subjek penelitian adalah pasien DM yang memenuhi kriteria inklusi yaitu pasien di Puskesmas Dawan I Tahun 2017, yang mampu membaca dan menulis, tidak sedang dalam kondisi menderita komplikasi (seperti gangren, Infarc Myocard Acute, Gagal Ginjal Kronis dan dalam kondisi penurunan kesadaran), tidak mengalami gangguan jiwa dan tidak mengalami dementia. Tehnik sampling yang digunakan adalah Purposive Sampling dengan jumlah sampel 85 orang. Sumber data primer didapatkan langsung dari responden dengan menggunakan kuesioner dan sumber data sekunder yang berasal dari data rekam medis.

Kuesioner pada penelitian ini menggunakan kuesioner The Diabetes Self-Management Questionnaire (DSMQ) (Schmitt, dkk, 2013) yang dimodifikasi oleh peneliti. DSMQ terdiri atas 16 pertanyaan dengan skala Likert 4 poin, yang mencakup 5 aspek manajemen diri diabetes, yaitu kepatuhan diet, kepatuhan medikasi, monitoring glukosa darah, aktivitas fisik, dan kepatuhan kontrol. Semakin tinggi skor mengindikasikan perilaku manajemendiri yang semakin diharapkan. Validitas diuji dengan confirmatory factor analysis (yang menunjukkan kesesuaian dengan model 4 faktor). Reliabilitas diuji dengan koefisien alpha Cronbach. Reliabilitas instrumen ini menunjukkan kepatuhan diet 0,79 , kepatuhan medikasi 0,75 , monitoring glukosa darah 0,83 , aktivitas fisik 0,74 , dan kepatuhan kontrol 0,72 (Schmitt, dkk, 2016). Pada penelitian ini, dilakukan uji validitas dan reliabilitas kembali dengan hasil uji validitasnya dengan $r$ dalam rentang $0,87 \mathrm{~s} . d$ 0,96 dan hasil uji reliabilitas alpha cronbach sebesar 0,97. Pada penelitian ini dikatakan perilaku pencegahan masuk kategori baik jika responden melakukan $\geq 80 \%$ aktifitas pencegahan, dan dikatakan cukup jika hanya melakukan $60-79 \%$.

Instrumen pengetahuan, sikap, dan perilaku dibuat sendiri oleh tim peneliti, terdiri atas 24 pertanyaan/pernyataan. Jenis jawabannya menggunakan skala likert dengan 4 point yang terdiri dari 8 pertanyaan tentang pengetahuan, 8 pertanyaan tentang sikap dan 8 pertanyaan tentang perilaku. Penghitungan skor dengan cara membagi skor yang didapat dengan total skor. Kategori pengetahuan, sikap dan perilaku dikelompokkan dengan rumus baik jika skor yang didapat $\geq 80$, sedang jika skor yang didapat antara 60-79 dan buruk jika skor yang didapat kurang dari 60 . Analisis data yang digunakan adalah analisis univariate dan bivariate (chi-square test). Etika penelitian tetap dijaga dengan cara pemberian informed consent, dan menjelaskan bahwa data yang digunakan hanya untuk penelitian, serta semua data akan dijamin kerahasiannya. Setelah data dikumpulkan subyek tetap diberikan penjelasan cara mencegah komplikasi. 


\section{HASIL}

Karakteristik subjek penelitian ini berdasarkan usia, jenis kelamin, tingkat pendidikan, dan pekerjaan (Tabel 1). Dari Tabel 1 dapat diketahui bahwa dari 85 responden rata-rata berusia yaitu 55,2 tahun. Rentang usia responden adalah 45-65 tahun. Berdasarkan jenis kelamin, 53 responden berjenis kelamin laki-laki $(62,4 \%)$. Tingkat pendidikan responden paling banyak berada pada tingkat pendidikan sekolah dasar (SD) yaitu $43,5 \%$. Jumlah responden yang tidak bekerja pada penelitian ini mencapai $34,7 \%$.

Berdasarkan tabel 2, tingkat pengetahuan responden paling banyak berada pada tingkat cukup (85,9\%). Sikap responden paling banyak berada pada tingkat cukup $(65,9 \%)$, dan tindakan paling banyak berada pada tingkat cukup $(67,1 \%)$. Hubungan perilaku pencegahan dengan kejadian komplikasi akut pada pasien DM ditampilkan pada Tabel 3. Berdasarkan tabel tersebut, $p$ value sebesar 0,003 , kurang dari alpha 0,05 . Hal ini artinya 95\% diyakini bahwa ada hubungan perilaku pencegahan dengan kejadian komplikasi akut pada pasien DM. Dari tabel tersebut diketahui pula bahwa ada sebanyak 26 responden yang memiliki perilaku pencegahan yang baik diantaranya 18 responden $(69,2 \%)$ tidak pernah mengalami komplikasi akut DM dan 8 responden $(30,8 \%)$ pernah mengalami komplikasi akut DM, sedangkan perilaku pencegahan cukup sebanyak 59 responden diantaranya 19 responden $(33,2 \%)$ tidak pernah mengalami komplikasi akut DM dan 40 responden $(67,8 \%)$ pernah mengalami komplikasi akut DM. Hasil analisis diperoleh pula nilai OR=4,737 artinya pasien DM yang memiliki perilaku pencegahan yang cukup mempunyai 4,73 kali untuk mengalami komplikasi akut pada DM.
Tabel 1. Karakteristik Responden

Berdasarkan Usia, Jenis Kelamin, Pendidikan, Pekerjaan

\begin{tabular}{lllll}
\hline Karakteristik & $\mathrm{f}$ & $\%$ & Mean & SD \\
\hline Usia (tahun) & 85 & 100 & 55,2 & 5,57 \\
Jenis kelamin: & & & &
\end{tabular}

Laki-laki $\quad 53 \quad 62,4$

- Perempuan $32 \quad 37,6$

Tingkat Pendidikan:

Tidak sekolah

$\begin{array}{lll}\text { - SD } & 37 \quad 43,5\end{array}$

$\begin{array}{lll}\text { - SMP } & 21 & 24,7\end{array}$

- SMA $\quad 17 \quad 20$

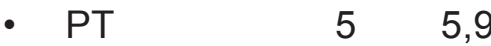

Pekerjaan:

- PNS

$18 \quad 21,2$

- Swasta

$20 \quad 23,5$

- Wiraswasta $16 \quad 18,8$

$\begin{array}{lll}\text { - Petani } 8 & 9,4\end{array}$

- Peternak 22,4

- $\quad$ Tidak bekerja $21 \quad 24,7$

Tabel 2. Tingkat pengetahuan, sikap, dan tindakan pasien DM

Pengetahuan, Sikap, dan Tindakan f $\quad \%$

Tingkat pengetahuan:

- Baik

1214,1

- Cukup

$73 \quad 85,9$

Sikap:

- Baik

2934,1

- Cukup

$56 \quad 65,9$

Tindakan:

- Baik

$28 \quad 32,9$

- Cukup

$57 \quad 67,1$ 
Tabel 3. Hubungan perilaku pencegahan dengan kejadian komplikasi akut pada pasien DM

\begin{tabular}{lcccccccc}
\hline \multirow{2}{*}{$\begin{array}{c}\text { Perilaku } \\
\text { pencegahan }\end{array}$} & \multicolumn{3}{c}{ Kejadian Komplikasi Akut DM } & Total & $\begin{array}{c}\text { OR } \\
(\mathbf{9 5 \%} \text { Cl) }\end{array}$ & p Value \\
\cline { 2 - 9 } & \multicolumn{2}{c}{ Tidak pernah } & \multicolumn{2}{c}{ Pernah } & & & & \\
\cline { 2 - 9 } & $\mathbf{n}$ & $\%$ & $\mathbf{n}$ & $\%$ & $\mathbf{n}$ & $\%$ & & 0,003 \\
Baik & 18 & 69,2 & 8 & 30,8 & 26 & 100 & & \\
Cukup & 19 & 32,2 & 40 & 67,8 & 59 & 100 & 4,737 & \\
Total & 37 & 43,5 & 48 & 56,5 & 85 & 100 & $(1,750-12,82)$ & \\
\hline
\end{tabular}

\section{DISKUSI}

Penelitian ini menunjukkan bahwa ada hubungan antara perilaku pencegahan dengan kejadian komplikasi akut pada pasien DM. Pasien DM yang memiliki perilaku pencegahan pada kategori cukup mempunyai 4,73 kali untuk mengalami komplikasi akut pada DM dibanding meraka yang berada pada kategori baik. Perilaku pencegahan dapat dikaitkan dengan pengetahuan. Penelitian Khairani (2012) yang dilakukan di Lam Bheu Aceh Besar menyimpulkan bahwa pengetahuan tentang faktor risiko sangat berpengaruh terhadap upaya pencegahan yang dilakukan lansia yang menjadi responden dalam penelitiannya.

Penelitian Azriana (2013) yang dilakukan pada 34 responden dengan penyakit DM di RSUD Cut Nyak Dhien Meulaboh tahun 2013 menunjukkan ada hubungan yang bermakna antara pengetahuan dengan pencegahan komplikasi DM. Selain itu Maghfiroh (2013) yang melakukan penelitian di Kelurahan Tandang Wilayah Kerja Puskesmas Kedungmundu Kota Semarang menyatakan bahwa pengetahuan seorang lansia yang jika dilihat berdasarkan tingkat pendidikannya adalah tamatan SD, hal tersebut tidak berpengaruh besar dalam perilaku pencegahan komplikasi karena semua itu tergantung dari sikap dan motivasi lansia tersebut terhadap perilaku pencegahan kejadian komplikasi DM.

Pada penelitian ini, pengetahuan lebih dari tiga perempat responden tentang penyakitnya berada pada tingkat cukup, sedangkan lebih dari setengah responden sikap dan tindakannya berada pada kategori cukup. Riset Kesehatan Dasar tahun 2013 yang dilaporkan oleh Kementerian Kesehatan RI (2013) menunjukkan bahwa dua pertiga penderita diabetes tidak mengetahui bahwa dirinya menderita DM. Hal ini tentu dapat memengaruhi perilaku pencegahan DM yang dilakukan. Penelitian yang dilakukan oleh Putri, Yudianto, \& Kurniawan (2013) menunjukkan bahwa dari 94 responden yang merupakan pasien DM di Poliklinik DM RSUD Sumedang, sebanyak $90,4 \%$ telah mendapatkan informasi terkait penyakit DM. Lebih lanjut dilaporkan bahwa responden yang mempunyai selfmanagement baik sebanyak 64,9\%.

Pemahaman pasien DM dalam mencegah terjadinya komplikasi akut sangat diperlukan untuk kualitas hidup pasien itu sendiri dan mengurangi biaya akan pengobatan pasien. Selain itu, dukungan dari orang lain juga diperlukan untuk dapat meningkatkan kualitas hidup pasien DM. Dukungan dari orang lain maksudnya adalah orangtua, anak, suami, istri atau saudara yang dekat dengan penderita, dengan 
bentuk dukungan dapat berupa informasi, tingkah laku tertentu atau materi yang dapat menjadikan individu merasa disayangi, diperhatikan dan dicintai (Mirza, 2017).

Notoatmodjo (2016) mengungkapkan bahwa sebelum orang mengadopsi perilaku baru, pertama kali yang terjadi di dalam dirinya adalah menyadari adanya stimulus, tertarik terhadap stimulus dan mempertimbangkan baik tidaknya stimulus tersebut bagi dirinya. Kemudian mencoba perilaku baru dan berperilaku sesuai dengan pengetahuan, kesadaran, dan sikapnya terhadap stimulus. Dalam hal ini, kesadaran diri sangat dibutuhkan sebagai dasar dalam meningkatkan pengetahuan dan merubah perilaku pasien DM agar terhindar dari komplikasi yang akan memperburuk keadaan sakitnya.

Yanti (2009) melaporkan bahwa hasil penelitiannya pada 69 responden penderita DM di RSUD dr. Adnan W.D. Payakumbuh menunjukkan kesadaran diri berhubungan secara bermakna dengan kejadian komplikasi DM. Lebih lanjut dilaporkan bahwa pada umumnya responden $(76,8 \%)$ sudah pernah mendapatkan penyuluhan tentang DM, tetapi masih banyak responden yang mengalami komplikasi. Penelitian ini menunjukkan bahwa ada hubungan antara penyuluhan dengan kejadian komplikasi. Pada responden yang tidak pernah mendapat penyuluhan, risiko mengalami kejadian komplikasi adalah 9 kali dibanding mereka yang pernah mendapatkan penyuluhan. Penyuluhan merupakan salah satu pilar manajemen DM yang sangat berpengaruh dalam penatalaksanaan DM dan pencegahan komplikasinya.

Penelitian-penelitian di atas menunjukkan bahwa pasien DM yang memiliki tingkat pengetahuan yang kurang sering mengalami komplikasi DM. Hal tersebut disebabkan oleh kurangnya pemahaman pasien DM tentang penyakitnya. Pasien DM hampir sebagian berusia lanjut, oleh karena itu faktor usia dapat membuat daya ingat pasien menurun. Pencegahan komplikasi akut dapat dihindari jika ada kesadaran diri pasien DM untuk mau mengubah sikap dan tindakannya. Jika komplikasi akut ini terjadi maka perlu penanganan yang tepat dan segera agar tidak menimbulkan kecacatan sampai kematian.

Pada penelitian ini, 56,5\% responden pernah mengalami kejadian komplikasi akut. Hasil ini lebih tinggi dibandingkan penelitian sebelumnya yang dilakukan oleh Riri (2015). Penelitian Riri (2015) melaporkan bahwa dari 195 kasus DM di Rumah Sakit Muhammadiyah Palembang pada tahun 2013, sebanyak 1\% menderita DM Tipe I dan 99\% menderita DM Tipe II. Dari penderita DM Tipe II tersebut, 83,9\% menderita komplikasi. Komplikasi akut diderita oleh 49 $(25,4 \%)$ penderita DM Tipe II. Lebih lanjut dilaporkan bahwa jenis komplikasi akut yang diderita responden adalah berupa Ketoasidosis Diabetik (KAD) $(21 ; 20,9 \%)$ dan hipoglikemia $(28 ; 14,5 \%)$.

Penelitian sebelumnya kebanyakan melaporkan adanya komplikasi kronis yang dialami penderita DM. Misalnya penelitian yang dilakukan oleh Musyawirah, Rismayanti, \& Ansar (2016) yang menunjukkan bahwa dari 120 orang dengan DM yang terdaftar di RS Ibu Sina pada tahun 2016, sebanyak 69,2\% mengalami komplikasi dengan rincian jenis komplikasi retinopati diabetik (12\%), neuropati diabetik $(42,1 \%)$, nefropati diabetik $(18 \%)$, penyakit jantung koroner $(10,8 \%)$, stroke $(13,2 \%)$, dan TB paru $(3,6 \%)$. Selain itu penelitian Restada (2016) melaporkan bahwa dari 125 responden penderita DM di wilayah kerja Puskesmas Gatak, sebanyak 58 orang menderita komplikasi retinopati, 40 orang menderita komplikasi neuropati, 11 orang menderita nefropati, 8 orang menderita jantung koroner, 6 orang mengalami stroke, 
dan 2 orang mengalami impotensi.

Tindakan pengendalian DM untuk mencegah komplikasi sangat diperlukan, khususnya dengan menjaga tingkat gula darah sedekat mungkin dengan normal. Selain itu, 5 aspek manajemen diri diabetes, yaitu kepatuhan diet, kepatuhan medikasi, monitoring glukosa darah, aktivitas fisik, dan kepatuhan kontrol perlu diajarkan kepada penderita DM. Perawat dapat berperan serta secara aktif pada kelima aspek manajemen diri diabetes tersebut.

Kelemahan dari penelitian ini adalah desainnya yang masih sangat sederhana dan jumlah sampelnya yang masih sedikit, sehingga perlu dilakukan penelitian dengan desain yang lebih baik dan jumlah sampel yang lebih proposional sehingga dapat memperkuat generalisasinya. Selain itu, instrumen yang dibuat oleh peneliti belum melalui proses uji validitas dan reliabilitas sehingga diperlukan pengujian lebih lanjut.

\section{SIMPULAN}

Ada hubungan perilaku pencegahan dengan kejadian komplikasi akut pada pasien DM. Perilaku pencegahan dapat mengurangi risiko komplikasi akut pada penderita DM type II, sehingga perilaku pencegahan menjadi hal yang sangat penting dilakukan oleh para klien penderita DM tipe II. Perawat perlu berperan aktif dalam memberikan asuhan keperawatan pada penderita DM Tipe II misalnya melalui 4 aspek manajemen diri diabetes.

\section{DAFTAR PUSTAKA}

Azriana. (2013). Faktor-faktor yang berhubungan dengan upaya pencegahan komplikasi diabetes mellitus oleh pasien diabetes mellitus di Rumah Sakit Umum Daerah Cut Nyak Dhien Meulaboh Kabupaten Aceh Barat (Skripsi). Program Studi IImu
Kesehatan Masyarakat, Fakultas Kesehatan Masyarakat, Universitas Teuku Umar, Aceh Barat, Indonesia.

Berber, A., Gomez-Santos, R., Fanghanel, G., Sanchez-Reyes, L. (2001). Anthropometric indexes in the prediction of type 2 diabetes mellitus, hypertension dan dislipidemia in a mexican population. Int $\mathrm{J} \mathrm{Ob-}$ ses Relat Metab Disord, 25(12): 1794-1799.

Dinas Kesehatan Kabupaten Klungkung. (2016). Surveilans terpadu penyakit berbasis puskesmas sentinel. Klungkung: Dinas Kesehatan Kabupaten Klungkung.

Goldman, L., \& Schafer, A. (2012). Hypoglycemia (disorder). Elsevier Inc. (online). Retrieved from http//:www.clinicalkey.com/topic/hypoglycaemia.

International Diabetes Federation. (2013). IDF Diabetes atlas sixth edition., IDF diabetes atlas (buku elektronik) (online). Retrieved from www.idf. org/diabetesatlas

Kementerian Kesehatan Republik Indonesia. (2013). Riset kesehatan dasar 2013. Jakarta: Badan Penelitian dan Pengembangan Kesehatan Kemenkes R.I.

Khairani. (2012). Pengetahuan diabetes mellitus dan upaya pencegahan pada lansia di Lam Bheu Aceh Besar. Idea Nursing Journal, 3(3): 57-65. Maghfiroh, A. (2013). Hubungan tingkat pendidikan dan pengetahuan dengan perilaku pencegahan komplikasi pada lansia diabetes mellitus (DM) di Kelurahan Tandang wilayah kerja puskesmas Kendungmundu Kota Semarang (Skripsi). Fakultas IImu Keperawatan dan Kesehatan Universitas Muhammadiyah Semarang, Semarang, Indonesia. 
Mirza, R. (2017). Memaksimalkan dukungan keluarga guna menginkatkan kualitas hidup pasien diabetes mellitus. Jurnal Jumantik, 2(2): 1230.

Musyawirah, D., Rismayanti, Ansar J. (2016). Faktor yang berhubungan dengan kejadian komplikasi DM pada penderita DM di RS Ibnu Sina. Retrieved from http://digilib.unhas. ac.id/uploaded_files/temporary/DigitalCollection/YTNiNjdIYjU2ZjhIMTU1YTMxYjdhZGVmZjhjZWMxMWQXOGI2YWI2Nw==.pdf

Notoadmojo, S. (2016). Metodologi pendidikan dan perilaku kesehatan. Jakarta: Rineka Cipta.

Puskesmas Dawan I. (2016). Surveilans kasus PTM di Puskesmas Dawan I. Dawan: Puskesmas Dawan I.

Putri, D.S.R., Yudianto, K., Kurniawan, T. Perilaku sef-management pasien diabetes mellitus (DM). Jurnal Keperawatan Padjajaran, 1(1): 30 38.

Restada, E. J. (2016). Hubungan lama menderita dan komplikasi diabetes mellitus dengan kualitas hidup pada penderita diabetes mellitus di wilayah puskesmas Gatak Sukoharjo (Skripsi). Program Studi S1 keperawatan, Fakultas IImu Kesehatan, Universitas Muhammadiyah Surakarta, Solo, Indonesia.

Riri, H. E. (2015). Angka kejadian dan karakteristik penderita diabetes mellitus dengan komplikasi yang dirawat inap di bagian penyakit dalam rumah sakit muhammadiyah Palembang periode 1 Januari 2013-31 Desember 2013 (Skripsi). Fakultas Kedokteran Universitas Muhammadiyah Palembang, Palembang, Indonesia.
Rizal \& Buana N. (2008). Faktor-faktor yang berhubungan dengan kejadian PJK pada penderita DM tipe 2 di RSUP DR. M. Djamil Padang (Skripsi). Program Studi IImu Keperawatan Universitas Andalas, Padang, Indonesia.

Schmitt, A., Gahr, A., Hermanns, N., Kulzer, B., Huber, J., \& Haak, T. (2013). The Diabetes Self-Management Questionnaire (DSMQ): development and evaluation of an instrument to assess diabetes self-care activities associated with glycaemic control. Health and quality of life outcomes, 11: 138. doi:10.1186/1477-7525-11138.

Schmitt, A., Reimer, A., Hermanns, N., Huber, J., Ehrmann, D., Schall, S., Kulzer, B. (2016). Assessing diabetes self-management with the diabetes self-management questionnaire (DSMQ) can help analyse behavioral problems relate to reduced glycaemic control. PLoS ONE 11(3): e0150774. https://doi. org/10.1371/journal.pone.0150774

Waspadji, S. (2009). Komplikasi kronik diabetes: mekanisme terjadinya, diagnosis dan strategi pengelolaan. Jakarta: PT Gramedia Pustaka Utama.

WHO. (2016). Global report on diabetes. Retrieved from https://apps. who.int/iris/bitstream/handle/ 10665/204871/9789241565257 eng.pdf;jsessionid=D22FC6F2337 E92719EB51C8FE18F5F72?sequ ence $=1$

Yanti, S. (2009). Analisis hubungan kesadaran diri pasien dengan kejadian komplikasi diabetes mellitus dalam konteks asuhan keperawatan di RSUD Dr. Adnan W. D. Payakum- 
buh (Tesis). Magister Ilmu Keperawatan Kekhususan Keperawatan Medikal Bedah, Program Pascasarjana Fakultas IImu Keperawatan, Universitas Indonesia, Depok, Indonesia. 